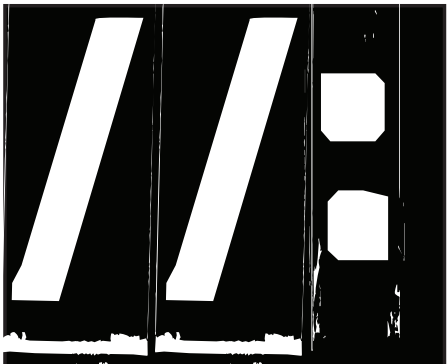

educa"ción y co"municación 18: 129-140 Mayo 2019

\section{SORORIDAD Y RESISTENCIA DIGITAL ANTE EL ACOSO SEXUAL GALLEJERO}

\section{Sorority and digital resistance to street sexual harassment}

\author{
María Escalona Castro \\ Graduada en Psicología (Universidad de Cádiz) \\ Máster Psicología de la Intervención Social (Universidad \\ de Granada) \\ E.mail: mescalona95@gmail.com
}

Resumen

El acoso sexual callejero es un tipo de violencia de género que impacta diariamente en el derecho de las mujeres a transitar libremente por el espacio público. Los medios de comunicación tradicionales han dado menos importancia al acoso cotidiano en el espacio público. Asimismo, cuando información relacionada con experiencias de violencia a mujeres generan más inseguridad por el contenido y la forma en que publican. Es decir, es parte de las fuentes de aprendizaje de la peligrosidad de la calle para ellas, amplificando el miedo. De forma paralela, en los últimos años está emergiendo una ola de activismo digital feminista que denuncia y explicita el acoso callejero. En este sentido, se hace un análisis de algunas iniciativas que han surgido en los medios alternativos de información y que promueven la conciencia sobre qué tipo de actitudes y comportamientos se entienden por acoso callejero, desde la propia voz de las afectadas.

Palabras clave: acoso sexual callejero; redes sociales; feminismo; medios de comunicación

\title{
Abstract:
}

Street harassment is a type of gender violence that daily affects the right of women to move freely in public space. Traditional media have given less importance to daily harassment in public space. In addition, when information related to the experiences of violence against women generates more insecurity due to the content and the way in which they publish. That is, it is part of the learning sources of danger on the street for them, amplifying fear. At the same time, a wave of feminist digital activism has emerged in recent years that denounces and explains street harassment. In this sense, we analyze some initiatives that have arisen in the alternative means of information and that promote consciousness about what kind of attitudes and behaviors are understood through street harassment, from the own voice of those affected.

Keywords: Street sexual harassment; social networks; feminism; media

Recibido 13-01-2019 / Revisado 25-01-2019 / Aceptado 22-03-2019 / Publicado 01-05-2019

https://doi.org/10.25267/Hachetetepe.2019.v1.i18.12 


\section{II: Feminismo y medios de comunicación}

\section{Introducción}

"El 50\% de las mujeres ha experimentado alguna forma de acoso sexual desde los 15 años" Agencia Europea de Derechos Humanos (2014)

$\mathrm{L}$ as mujeres y los hombres hacen un uso diferencial y desigual del espacio público. La Teoría Biosocial (Wood y Eagly, 2002) explica cómo históricamente las mujeres han sido segregadas al espacio privado-reproductivo y excluidas del público-productivo, mientras los hombres dominaban en todos los niveles ecológicos que sustentan el orden patriarcal. Si bien las mujeres han ido ganando terreno en lo público-productivo al incorporarse al mercado laboral, aún está en desventaja, por ejemplo, con la brecha salarial de género, siendo este un mecanismo de perpetración de la desigualdad.

Además de este ejemplo, un hecho que afecta a todas las mujeres, sean empleadas o desempleadas, jóvenes o adultas, es la falta de libertad en la circulación como ciudadanas en la vía pública. Esto se debe a comportamientos y actitudes perpetradas por hombres y conceptualizadas como acoso sexual callejero (Bowman, 1993).

La experiencia y la movilidad por el espacio público están, por tanto, condicionadas por el género. Es decir, las mujeres, además de estar expuestas a peligros incívicos (e.g., robo o asalto), lo están a diferentes comportamientos cotidianos expresados en palabras, sonidos, roces, tocamientos $y / o$ persecuciones que afectan al modo en que perciben su seguridad en la calle. En este sentido, se habla de dominancia masculina del espacio público, ya que estos actos recuerdan a la mujer que ese no es su lugar y que, si se expone en él, su cuerpo se hace accesible y puede ser tocado, comentado e incluso violado (Billi, Guerrero, Meniconi, Molina, y Torrealba, 2014).

El acoso sexual callejero, lejos de ser propio de determinadas sociedades, se trata de un fenómeno transcultural y transnacional (Lennox y Jurdi-Hage, 2017). En el territorio español, aunque la macroencuesta de género no especifica datos sobre acoso sexual callejero en el cotidiano, existen estudios cualitativos que recogen cómo las mujeres jóvenes informan ser objeto de comentarios incómodos, insistencias, tocamientos, forcejeos y acorralamientos de forma habitual en contextos de ocio y drogas (Observatorio Noctámbulas, 2017).

\section{Definición de Acoso Sexual Callejero}

El Acoso Sexual Callejero lo definía Cynthia Bowman como: el "acoso [sexual] a mujeres en lugares públicos por hombres desconocidos" (Bowman, 1993: 519).

En 2013 las Naciones Unidas expuso la necesidad de reconocer el acoso sexual en el espacio público como un tipo de violencia por razón de género (Un Women, 2014). Se caracteriza por: (a) las mujeres son el objetivo del acoso; (b) quienes ejercen el acoso son hombres; (c) los acosadores no conocen a las mujeres a las que se dirigen; (d) el encuentro se produce cara a cara; (e) el espacio es cualquier lugar público (e.g., la calle, transportes públicos o cualquier lugar donde haya acceso para las personas); (f) el contenido del discurso, si lo hay, no pretende ser público sino orientado hacia la mujer objetivo; y (g) se trata de un acto degradante y que cosifica, humilla y amenaza a la mujer.

En el acoso callejero se diferencia el tipo visual, que 


\section{1/: Sororidad y resistencia digital ante el acoso sexual callejero}

refiere comportamientos como miradas al cuerpo que incomodan a la mujer, gestos sexuales y obscenos; acoso verbal, como abucheos, silbidos y comentarios, ya sean "positivos", ofensivos o insultantes; y el acoso referido a intromisiones físicas (McCarty, Iannone y Kelly, 2014).

Las mujeres, por lo general, llevan a cabo diversas estrategias para sentirse más seguras en la calle debido a que cuando transitan solas, sobre todo en contextos nocturnos, sienten emociones negativas como miedo (Livingston, Grillo y Paluch, 2015). Según algunas autoras, el miedo generalizado que emerge en la vía pública por parte de ellas, tiene varias fuentes.

\section{Fuentes del miedo}

Las mujeres desde la infancia son advertidas por sus familias del grave peligro que corren si se encuentran en la calle solas. Sin embargo, los niños no reciben ese mensaje. Por tanto, una de las principales fuentes del miedo reside en la propia socialización de género en la que sutilmente se va construyendo en el imaginario colectivo de ellas "la calle no es tuya", estando ausente en ellos esta limitación (Rodó-de-Zárate y Castany, 2016).

Por otro lado, cobra fuerza el miedo a través de las propias experiencias vividas en la calle por ellas, sobre todo, el acoso en forma del tradicional piropo. La literatura expone cómo la mayoría de las mujeres sienten emociones negativas (e.g., miedo, ansiedad, vergüenza, irritación) (Fernández, 2016) ante este tipo de acoso verbal, socialmente considerado inocuo. Estas experiencias van creando en ellas una indefensión aprendida ya que, lejos de poder controlar recibir atención no deseada por parte de los hombres, su inseguridad percibida reside en el simple hecho de ser mujeres. Es por esto que hablamos de violencia machista en las calles.

Por último, y aquí reside el interés de análisis en este texto, se habla del miedo fruto de la alarma social (Rodó-de-Zárate y Castany, 2016). En este sentido, los medios de comunicación son una fuente importante de transmisión de información relacionada con experiencias traumáticas de las mujeres en la calle. Sobre todo, en relación a noticias de violaciones y asesinatos.

\section{Medios de comunicación: amplificación del miedo}

Un ejemplo es el caso de D.Q. que fue asesinada por un hombre desconocido. En los medios de comunicación se expusieron los últimos mensajes de WhatsApp que ella envió a sus amistades y que decía que estaba asustada porque un desconocido le estaba diciendo "ven, morena". Si se analiza el mensaje podría pasar por un comentario cotidiano análogo a un "piropo", por lo que es fácil que las mujeres después de conocer este tipo de sucesos conecten directamente la recepción de un piropo con la idea de una posible agresión. Lejos de cuestionar la difusión de este tipo de información en los medios, ya que visibilizar la violencia machista es una necesidad, sí es importante analizar el impacto del contenido de las noticias sin que haya un discurso paralelo que sensibilice y fomente la igualdad de las mujeres, como diría Marcela Lagarde:

«El papel de los medios de comunicación es crucial en la violencia contra las mujeres (...) por su alta incidencia y su influencia en la orientación y la formación de la opinión, en particular del sentido común (...) son 
claves porque educan en la aceptación de la violencia contra las mujeres e incluso en las formas de realizarla al difundir, por un lado, actos y modalidades de este tipo (...) y al tratar de manera amarillista, por otro, los atentados contra las mujeres» (Lagarde, 2007: 219-220).

Sin embargo, sí se puede hablar de la amplificación del miedo causado por la forma y contenido de las noticias, de la correcta transmisión de las agresiones. Es decir, los medios de comunicación no siempre hacen una justa presentación real de todos los tipos de violencia hacia las mujeres ya que pasa desapercibida, por ejemplo, el acoso callejero que sucede todos los días y a todas horas. Además, exponen otros sucesos que pueden conectar ideas que perturban la seguridad percibida por ellas.

\section{La resistencia en los medios alternativos de infor- mación: Activismo digital}

Ante medios de comunicación que contribuyen a la percepción de inseguridad en las calles, las mujeres han ocupado los medios alternativos de información como forma de resistencia y visibilización. El feminismo es uno de los movimientos que más impacto está teniendo en este tipo de medio, encontrando en las TICs una de sus mejor aliadas.

Las mujeres, a título personal o desde colectivos, han tejido redes como vía de denuncia del acoso callejero en Twitter, Facebook y Youtube. Por ejemplo, en España se relataron miles de episodios de acoso a través del Hastag "\#cuéntalo" o \#MeToo (yo también) en Twitter. Esta forma de promover narrativas contribuye a construir identidad grupal, promoviendo la acción colectiva (Harlow, 2013). De hecho, las narrativas son fundamentales en los movimientos sociales (La Rosa, 2016). Es decir, en la medida en que se pone de manifiesto las similitudes de las vivencias personales, se hace comprender que lo personal, es político en tanto que sus experiencias están atravesadas por el hecho de ser mujeres y vivir en desigualdad. Asimismo, se tejen redes emocionales internacionales.

Otro ejemplo es el video viral de una chica que graba su caminata por Nueva York en el cual se cuantifican hasta cien ocasiones en las que es víctima de acoso callejero, sobre todo en el formato visual/verbal. Esta estrategia de visibilización es posible en los medios alternativos ya que los medios tradicionales no exponen el acoso en espacios públicos de manera justa (Cordobés, 2017) sino de una forma sutil y con campañas más orientadas a que ellos no acosen y no a que ellas se empoderen (campaña No seas Animal, Junta de Andalucía).

\section{Rol movilizador de las redes sociales}

En este sentido, Gerbaudo (2012) habla de la función movilizadora de los medios sociales y destaca el rol de las emociones en la construcción simbólica del imaginario colectivo y el sentido de pertenencia social de las mujeres. En esta línea, explica que esto contribuye a dibujar la "coreografía social" de los movimientos sociales contemporáneos (La Rosa, 2016).

El caso del acoso callejero es especialmente sensibilizador debido a que, aunque haya mujeres que vivan la cosificación de forma positiva (Liss, Erchull y Ramsey, 2011), es un fenómeno que todas pueden identificar fácilmente como algo personal, debido a la falta de seguridad en la vía pública y todas las medidas pre- 


\section{1/: Sororidad y resistencia digital ante el acoso sexual callejero}

ventivas que han de desplegar (e.g., cambiar de ruta, pedir compañía a casa, no salir solas, etc) (Rodó-deZárate y Estivill, 2016). Por tanto, su denuncia puede calar fácilmente en las mujeres.

Además, las redes sociales permiten visibilizar acciones directas, como estrategias de afrontamiento activas de las mujeres los acosadores e.g., mirar con enojo, gritar, defenderse (Fairchild y Rudman, 2008). Es el ejemplo de la cuenta de Instagram "dearcatcallers" (queridos piropeadores) gestionada por una mujer holandesa que se hacía selfies con los hombres que la acosaban (verbal, visual o física) y que titulaba las imágenes con las frases u onomatopeyas lanzadas por los acosadores. Esta iniciativa instaba a otras mujeres a denunciar el acoso cotidiano, fomentando la concienciación y la acción colectiva.

Por otro lado, existen canales de Youtube de mujeres que hacen videos con Tips para enfrentar el acoso callejero y que enumera una serie de comportamientos de prevención. En este caso, promueven tanto estrategias de afrontamiento activas como pasivas, en función del tipo de acoso. Si bien esto genera seguridad y acompañamiento grupal, cabe preguntarse qué impacto tiene recibir mensajes de "ponte a salvo" en vez de "la calle es también tuya".

Si el acoso sexual callejero es una realidad ¿Cuál es el mensaje positivo y empoderador? ¿Aquel que te insta a denunciar tus agresores o aquel que te aconseja cómo ignorar el acoso y ponerte a salvo? ¿Confrontar te hace sentir más control de la situación? ¿Ignorar genera menos posibilidades de escalada por parte del agresor? En este sentido sería interesante estudiar qué tipo de mensajes favorecen el bienestar psicológico de las mujeres en términos de sensación de seguridad en la vía pública.

\section{Conclusión}

El acoso sexual callejero es una violencia muy visible e invisibilizada a su vez. Esto se debe a la naturalización de ciertos comportamientos como los tradicionales piropos al considerarse no perjudiciales para las mujeres. Si bien, las mujeres de todo el mundo han expuesto el malestar que les genera el constante hostigamiento cotidiano.

La violencia por razón de género es un tema de responsabilidad social. Si los medios de comunicación no han sabido visibilizar la gravedad del fenómeno, surgen con voz propia las narrativas en los medios alternativos de comunicación. Si bien, algunas iniciativas han causado polémica. Por ejemplo, se expone el derecho a no ser grabado sin consentimiento (en \#dearcatcallers) o la propia libertad de expresión, sobre todo en relación con los piropos. Sin embargo, se hace necesario recurrir a la expresión "mi libertad termina donde empieza la tuya", para problematizar estas demandas de derechos. Aun así, no está exento de dificultades mostrar contenido en este formato.

Por último, se considera necesaria la aparición de referentes con nuevas masculinidades que conciencien del no a la cultura del piropo y el acoso, en paralelo a las redes que se van tejiendo entre mujeres de todo el mundo al compartir sus narrativas, con el fin de minimizar estos comportamientos propios de la masculinidad hegemónica y machista.

\section{Referencias}

Fairchild, K., y Rudman, L. A. (2008). Everyday stranger harassment and women's objectification. Social Justice Research, 21(3); 338-357. 


\section{II: Feminismo y medios de comunicación}

Billi, M., Guerrero, M. J., Meniconi, L., Molina, M., y Torrealba, F. (2014). Masculinidades y legitimaciones del acoso sexual callejero en Chile. En Lamadrid, S. (Coord. Principal), Relaciones de género en el siglo XXI: Cambio y continuidades. Grupo de trabajo llevado a cabo en el $8^{\circ}$ Congreso Chileno de Sociología. Bowman, C. (1993). Street Harassment and the Informal Ghettoization of Women. Cornell Law Faculty Publications, 3(106); 517-580.

Fernández, N. (2016). Street harassment effects on women: An exploratory study (Tesis Doctoral). California State University: Long Beach.

Gerbaudo, P. (2012). Tweets and the streets: Social media and contemporary activism. Londres: Pluto Press.

Harlow, S. (2013). “It was a 'Facebook revolution': Exploring the meme-like spread of narratives during the Egyptian protests". Revista de Comunicación, 12; 59-82.

La Rosa, A. (2016). Movimientos sociales, redes sociales y recursos simbólicos. Correspondencias \& análisis, (6); 47-60.

Lagarde, M. (2007). Por los derechos humanos de las mujeres: la Ley General de Acceso de las Mujeres a una Vida Libre de Violencia. Revista Mexicana de Ciencias Politicas y Sociales, v. XLIX, 200; 143-165. Lennox, R., y Jurdi-Hage, R. (2017). Beyond the empirical and the discursive: The methodological implications of critical realism for street harassment research. Women's Studies International Forum, 60; 28-38.
Liss, M., Erchull, M. J., y Ramsey, L. R. (2011). Empowering or oppressing? Development and exploration of the Enjoyment of Sexualization Scale. Personality and Social Psychology Bulletin, 37(1); 55-68.

Livingston, B. A., Grillo, M., y Paluch, R. (2015). Street harassment: The largest international crosscultural study. Ithaca, NY: Cornell IRL.

McCarty, M. K., Iannone, N. E., y Kelly, J. R. (2014). Stranger danger: The role of perpetrator and context in moderating reactions to sexual harassment. Sexuality \& Culture, 18(4); 739-758.

Observatorio Noctámbulas (2017). Espacio público, violencias sexuales y ocio nocturno. Recuperado de: https://www.drogasgenero.info/noctambulas/informes/

Rodó-de-Zárate, M., y I Castany, J. E. (2016). ¿La calle es mía? Recuperado de: https:/www.naiz.eus/ media/asset_publics/resources/000/335/761/original/20161 102estudio-la-calle-es-mia.pdf

Un Women. (2014). Safe Cities Global Initiative brief. Recuperado de: http://www.unwomen.org/ /media/ headquarters/attachments/sections/library/p ublications/2014/un\%20women \%20safe \%20cities \%20 brief-us-web.pdf

Wood, W., y Eagly, A. H. (2002). A cross-cultural analysis of the behavior of women and men: implications for the origins of sex differences. Psychological bulletin, 128(5); 699. 